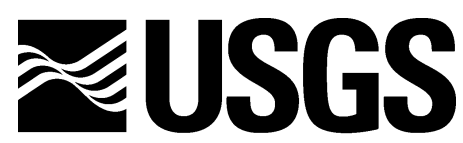

science for a changing world

In Cooperation with the World Bank, the Mauritania Ministry of Mines and Industry, and Futures Group

\title{
Hydrologic Modeling Strategy for the Islamic Republic of Mauritania, Africa
}

By Michael J. Friedel

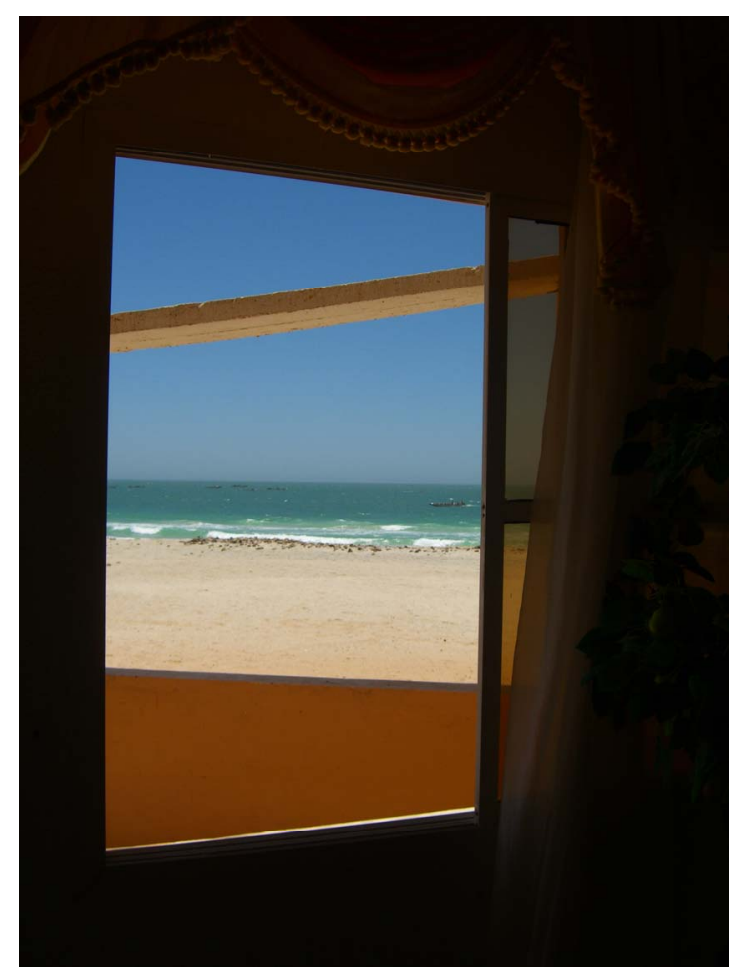

Open-File Report 2008-1173

U.S. Department of the Interior

U.S. Geological Survey 


\section{U.S. Department of the Interior DIRK KEMPTHORNE, Secretary}

\section{U.S. Geological Survey \\ Mark D. Myers, Director}

U.S. Geological Survey, Reston, Virginia 2008

For product and ordering information:

World Wide Web: http://www.usgs.gov/pubprod

Telephone: 1-888-ASK-USGS

For more information on the USGS - the Federal source for science about the Earth, its natural and living resources, natural hazards, and the environment:

World Wide Web: http://www.usgs.gov

Telephone: 1-888-ASK-USGS

Suggested citation:

Friedel, M.J., 2008, Hydrologic modeling strategy for the Islamic Republic of Mauritania, Africa: U.S. Geological Survey Open-File Report 2008-1173, 20 p.

Any use of trade, product, or firm names is for descriptive purposes only and does not imply endorsement by the U.S. Government.

Although this report is in the public domain, permission must be secured from the individual copyright owners to reproduce any copyrighted material contained within this report. 


\section{Contents}

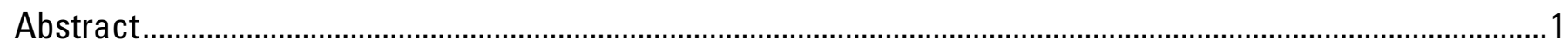

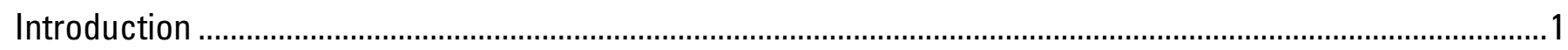

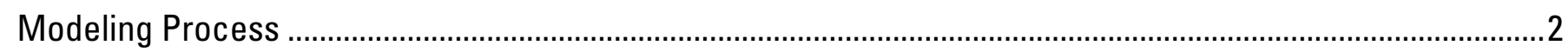

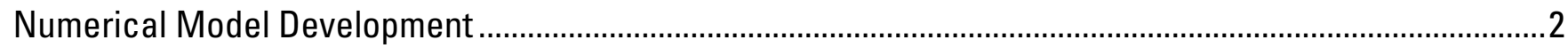

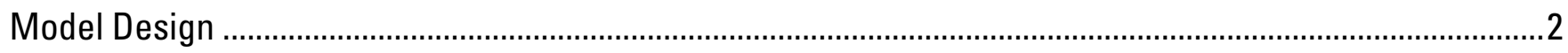

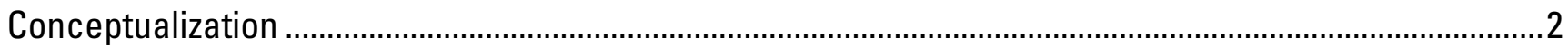

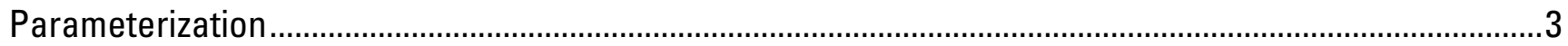

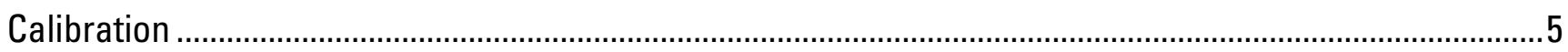

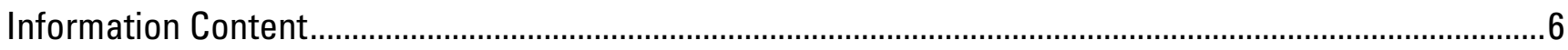

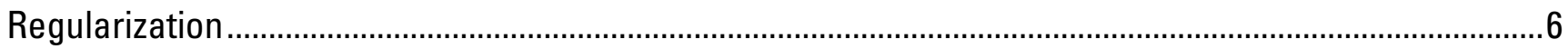

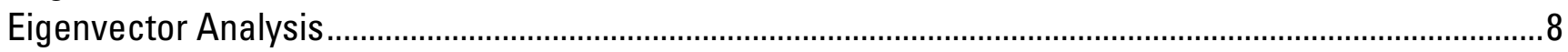

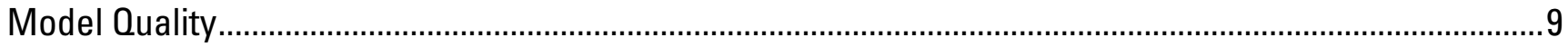

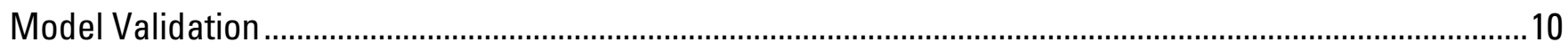

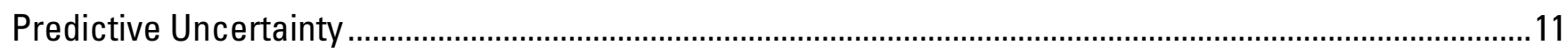

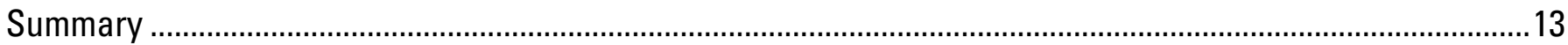

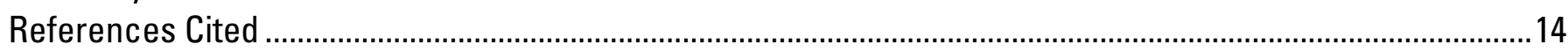




\title{
Hydrologic Modeling Strategy for the Islamic Republic of Mauritania, Africa
}

\author{
By Michael J. Friedel
}

\section{Abstract}

The government of Mauritania is interested in how to maintain hydrologic balance to ensure a long-term stable water supply for minerals-related, domestic, and other purposes. Because of the many complicating and competing natural and anthropogenic factors, hydrologists will perform quantitative analysis with specific objectives and relevant computer models in mind. Whereas various computer models are available for studying water-resource priorities, the success of these models to provide reliable predictions largely depends on adequacy of the model-calibration process. Predictive analysis helps us evaluate the accuracy and uncertainty associated with simulated dependent variables of our calibrated model. In this report, the hydrologic modeling process is reviewed and a strategy summarized for future Mauritanian hydrologic modeling studies.

\section{Introduction}

The government of Mauritania is interested in understanding how to maintain hydrogeologic balance to ensure a long-term stable water supply for minerals-related, domestic, and other purposes. Because of the many complicating and competing natural and anthropogenic factors, the surface- and ground-water resources are believed to be spatially variable in quantity and quality (British Geological Survey, 1996). Hydrologists will perform quantitative analysis with specific objectives and relevant computer models in mind. These objectives need to be developed based on the suggested national water-resource priorities: (1) protecting and expanding the groundwater supply for Nouakchott, the capital of Mauritania; (2) increasing mineral industry water supplies; (3) increasing rural water supplies; and (4) devising ground-water recharge strategies. The success of computer models to provide reliable predictions depends on the modeling process. In this report, the modeling process is summarized for future application to Mauritania. 


\section{Modeling Process}

The process of modeling the subsurface transport of mass and energy involves four primary components: numerical model development, model design, model validation, and model predictive analysis. The following sections provide an overview of these modeling components as well as a current set of references.

\section{Numerical Model Development}

Development of a numerical model begins by deriving the governing equations that describe the multidimensional transport of mass or energy, or both, in a basin. The complexity and nature of these equations depends on the objective and the water-resource setting, such as transport in surface water, ground water, the unsaturated zone, and the variably saturated zone. In some cases, multiple equations are coupled and solved to describe multiphase water flow and the simultaneous transport and interaction of water, chemicals, and heat in these settings. Because analytical solutions are typically available only for simplified equations and boundary conditions, the governing equations are converted to a numerical equivalent using one or more methods, such as analytic-element, boundary-element, finite-element, or finite-difference methods. These numerical equations are then coded, using a computer language, into a numerical model that is applied following model design, validation, and prediction analysis.

\section{Model Design}

Computer models have become a ubiquitous part of hydrologic analysis. Unfortunately, uncertainty is common in hydrologic models due to an imperfect model design process. The ability to minimize the introduction of uncertainty into our hydrologic models requires an understanding of the model design process. An overview of the model design process that includes conceptualization, parameterization, information content, regularization, eigenvector analysis, and model quality is provided in the following sections.

\section{Conceptualization}

At the foundation of all hydrologic models (whether basin, groundwater, variably saturated, or combinations thereof) is a conceptual model-the basic idea or construct of how the system or process under study operates. Using the principle of parsimony, a hydrologist seeks the simplest 
model that is consistent with available data. As a result, the conceptual model reflects the hydrologist's subjective idea of how to simplify reality. No single conceptual model is necessarily correct; however, some may be more correct than others. Because a conceptual model contains qualitative and subjective interpretations, its validity cannot be tested until a numerical model is constructed and comparisons between field observations and model simulation results are made. Thus, a numerical model is used to test and improve the conceptual model of a field site. The numerical model also can guide future data collection, particularly where additional data are needed to produce a conceptual model consistent with field observations. In this way, conceptual and numerical modeling should be viewed together as an iterative process where the conceptual model is reformulated using additional new insights and information from future or other field studies.

To study infiltration or recharge, ground-water hydrologists often develop and use complex models, such as field models of variably saturated zones (Izbicki and others, 2000; Pang and others, 2000) rather than laboratory models of simple unsaturated zones (Simunek and others, 1998). The argument for using a complex model is often based on recognizing the coupled interaction between multiple dependent variables, accounting for spatial and temporal heterogeneities, and wanting predictions beyond the calibration conditions. A coupled model that simulates a complex, variably saturated zone, such as the West African Sahara sand dune system, will require a greater number of estimated parameters than does a simple model, as a consequence of the additional coupled governing equations needed to represent spatial heterogeneity and temporal variation.

\section{Parameterization}

After a conceptual model is identified, the numerical model parameterization proceeds by supplying parameter values that control the simulated rate exchange of fluxes within the hydrologic system. These values come from direct or indirect sources, or both. Many laboratory and field methods allow direct determination of volume-averaged point hydraulic parameter values. For water supply problems, simple models of subsurface geology and direct bulk values of hydraulic parameters may suffice. As the focus shifts to contaminant transport problems where contaminant travel time is important, more complex models of the subsurface may be necessary. For example, lithologic facies may account for the largest permeability contrasts. In that case, conditional simulation of facies distributions (where alternate realizations are produced, and known values and statistics are maintained) may be important in parameterization of the numerical model. Because it is not possible to drill enough holes to confidently state that particular features exist or not at a site, 
soft prior information and stochastic simulation techniques can be used to improve the subsurface characterization. The stochastic techniques used this way are mostly continuous geostatistical models (Shafer and Varljen, 1990; Dietrich and Osborn, 1991), or discontinuous facies models such as Boolean indicator (Bui and Moran, 1995; Benito and Beucher, 2002), and the Markov-Chain method (Clifford, 1993; Chen and others, 2004).

Geostatistical techniques are widely used to produce geologically plausible realizations of facies and other hydrologic variables (such as parameter and property values). Reasons for using these techniques are that: (1) they provide a framework for considering sample support; that is, data that are averages over different support; (2) they provide a means to constrain the inverse procedure to estimate parameter values; and (3) they provide a Monte Carlo technique that can be used to generate realizations for assessing the consequences of uncertainty on flow and transport in a heterogeneous system. There are two challenges, however, in using geostatistical techniques. The first is the tacit assumption that all relevant heterogeneities and structures can be captured by a covariance. Substantive data sets are needed to develop models of spatial variability by empirical curve-fitting to sample indicator cross- (co)variograms. The second challenge is that the sequential indicator simulation method, a commonly used geostatistical technique, does not accurately produce patterns of spatial variability for systems having three or more facies (Seifert and Jensen, 1999).

Whereas the emphasis of geostatistics is on spatial variability, hydrogeologic variables may fluctuate in time as well as in space. Rouhani and Myers (1990) and Rouhani and Wackernagel (1990) discussed how to model variables that change with time, using empirically derived variograms. Desbarats and Bachu (1994) presented a geostatistical analysis of the spatial structure of hydraulic conductivity, from scales increasing from core to well to basin, for a sandstone hydrostratigraphic unit in Canada. They also describe upscaling from local conductivity to local transmissivity (upscaling through integration over the vertical direction) and increasing to macroscopic transmissivity.

Like traditional geostatistical techniques, the Markov chain method uses conditional simulation on sparsely observed data (Elfeki and Dekking, 2001; Liu and others, 2004; Zhang and $\mathrm{Li}, 2005)$. In contrast, however, variations in the Markov chain are used to devise transition probabilities for conditional simulation (Carle and Fogg, 1996). This approach is essentially an extension of indicator kriging, where the indicator variograms (or covariances) are replaced by transition probabilities used to generate simulated realizations. Another application of Markov 
random fields is used for simulated annealing (Norberg and others, 2002). These two techniques provide: (1) conceptual understanding of parameters in the spatial variability model, so that geologic insight can support and enhance model development when data are sparse; (2) mathematical rigor, so that the co-regionalized model (including the spatial cross-correlations) obeys probability law; and (3) consideration of spatial cross-correlation, so that juxtapositional tendencies - how frequently one facies tends to occur adjacent to another facies - are honored.

\section{Calibration}

A common alternate technique for the direct or stochastic estimation of parameter values (model calibration) is an objective mathematical approach, such as nonlinear regression, genetic algorithm, or simulated annealing. These methods of model calibration are based on fitting a simulated sequence of state variables to a measured time sequence. Whereas in the direct approach heterogeneity is defined by a set of measured, often interpolated, averaged values at local wells, in the indirect estimation approach heterogeneity is neither defined nor prescribed. The description of heterogeneity is based on local averaged measurements, and its distribution in space is inferred by the model calibration procedure.

Three indirect model calibration approaches are commonly used to solve multi-state inverse problems associated with mass and energy transport (Inoue and others, 2000). In the first approach, the inverse process is uncoupled, requiring two separate inverse problems to be solved. The estimated parameter values from an inverse solution to the flow equation (for example, hydraulic conductivity) are used as input to a second inverse problem, where parameter values for either a heat or solute transport equation are estimated (for example, thermal conductivity or dispersivity) (Mishra and others, 1989). In the second and most common model calibration approach, the flow and transport equations are loosely coupled through the sequential inverse solution of both equations at a given nonlinear parameter estimation iteration (Medina and Carrera, 1996; Abbaspour and others, 1997; Simunek and others, 1998a; Inoue, and others, 2000; Bravo and others, 2002; Gandhi and others, 2002). In the third approach, parameter values are estimated simultaneously using a set of governing equations that are implicitly coupled through their dependent variables for ground water (Sun and Yeh, 1990) and variably saturated zone transport (Friedel, 2002; 2005). Whereas these nonlinear approaches have been limited largely to two-state subsurface transport inverse problems (water flow and solute transport, or water flow and heat transport), model calibration using the sequential approach has been applied to multicomponent 
reactive groundwater (Essaid, and others, 2003) and variably saturated transport (Gaganis and others, 2002).

\section{Information Content}

Unfortunately, attempts to calibrate more complex field models under steady-state conditions (e.g., Hughson and Yeh, 1998) or transient conditions (e.g., Friedel, 2002, 2005) often result in estimated parameter values with a high degree of uncertainty (poor parameter identifiability). One way of resolving this problem in transport models for groundwater (Woodbury and Smith, 1988; Sun and Yeh, 1990; Medina and Carrera, 1996) and variably saturated zones (Abbaspour and others, 1997; Friedel, 2002, 2005) is to estimate parameter values while calibrating a coupled model against multiple types of coupled dependent variables. This method facilitates the crossover of information between dependent variables (the crossover effect), and its success is commonly evaluated through observed reductions in transport parameter uncertainty (Sonnenberg and others, 1996; Hendricks-Franssen, H.J. and others, 2003; Friedel, 2002, 2005, 2006a, 2006b).

Field studies demonstrate the inadequacy of calibration information on parameter uncertainty under transport conditions for steady-state ground water (Hughson and Yeh, 1998) and transient variably saturated zones (Friedel, 2002, 2005). Understanding the effect of limited spatial and temporal field information on parameter uncertainty in flow and transport modeling is important for predicting comparatively small fluxes through the variably saturated zone, particularly as attempts are made to model increasingly complex spatial heterogeneity. Compositescaled sensitivities allow us to evaluate the quantity of information available for estimating parameter values, and the likely importance of each parameter for predictions of interest (Mehl and Hill, 2001). If the information quality is comparatively poor (that is, limited in one or more of the following: number, type, space, and time), the calibration process may become numerically intractable. In general, the limited information content of field measurements used to constrain the model calibration process requires some form of regularization (Tikhonov, 1977; McLaughlin and Townley, 1996; Friedel, 2002, 2005, 2006a, 2006b).

\section{Regularization}

Regularization is a mathematical approach that can stabilize an overparameterized model and potentially extract more information from measurements used to constrain the calibration process. This is done by adding more information to the typically underdetermined system of field 
equations that must be inverted. Whereas the introduction of measurements as direct prior information represents an implicit form of regularization, this form is not preferred. The primary disadvantage in this method is the introduction of an unknown and permanent amount of structural noise (uncertainty). A preferred regularization strategy is to allow only simplifications that are necessary to achieve numerical stability in the parameter estimation process itself (McKenna and others, 2003; Friedel, 2005, 2006a, 2006b). Variations of this strategy common in inverse transport modeling include the use of prior parameter estimates and their statistics or else kriging in conjunction with pilot points (Hoeksema and Kitanidis, 1984; Carrea and Neuman, 1986a, 1986b; McKenna and others, 2003; Friedel, 2002, 2005, 2006a, 2006b).

Despite the stability and potential extraction of information content during a regularized inversion, the estimated parameter values are recognized as nonunique (Pang, 2000; Friedel, 2002, 2006a; McKenna and others, 2003). Parameter nonuniqueness reflects the fact that it is possible to calibrate a model that can be designed using one of a valid set of optimal measurements with optimal yet alternate sets of parameter values. The four potential reasons for parameter nonuniqueness in model calibration are: (1) lack of numerical precision, (2) numerical dispersion, (3) global and local minima in parameter space, and (4) correlation among model parameters. Friedel (2006b) provides a review of solutions that avoid parameter nonuniqueness caused by the first three reasons. The most difficult and elusive factor influencing parameter nonuniqueness, however, is the fourth reason: correlation among parameters.

Parameter correlation contributes to nonuniqueness because two or more parameters can vary in such a way as to have virtually no net effect on the calibration function. Correlation among parameters can occur because of model nonlinearities (either explicit or implicit) or insufficient information to resolve parameters values. Explicit nonlinearities occur naturally when converting the partial differential equations to a numerical equivalent. As a result, parameter values form ratios that were previously isolated. Implicit nonlinearities occur when a parameter is a function of one or more dependent variables, such as moisture content, which in arid climates can be a function of pressure head, concentration, and temperature. One consequence of correlation among parameters in subsurface transport models is the nonuniqueness of estimated parameter values despite their optimality in the least-squares sense (Friedel, 2002, 2005, 2006b). Because calibrated ground-water or variably saturated model parameter values are likely to be nonunique despite their optimality, flow and transport predictions made using a calibrated model also are likely to be nonunique and therefore uncertain. The issue of parameter-value nonuniqueness in inverse modeling is discussed 
for synthetic groundwater transport in McKenna and others (2003) and for variably saturated zone transport in Friedel $(2002,2005)$.

\section{Eigenvector Analysis}

The interrelation between pair-wise parameter correlation and parameter uncertainty has been conceptualized for ground-water transport using the linear confidence ellipse (Carrera and Neuman, 1986b). The confidence ellipse represents a prescribed level of certainty associated with the two-parameter response surface for which the idealized objective function minimum is a point. At this level of uncertainty, the linear confidence ellipse is defined by semiaxes (eigenvectors) whose magnitudes are proportional to the square roots of eigenvalues derived from the covariance matrix. Whereas the angle between the major and minor eigenvalues and horizontal axis describes the degree of correlation between parameters, the ratio of major to minor eigenvalues (called the condition number) describes the relative magnitude of model uncertainty. In general, larger condition numbers represent greater model uncertainty. The actual magnitude of parameter uncertainty associated with a particular eigenvector is given by the probability distributions that define the extent of the confidence contour.

A two-parameter response surface associated with the coupled inverse modeling of waterheat-solute transport within variably saturated zones appears very different than the conceptualized linear response surface (Friedel, 2005). These differences are attributed primarily to intrinsic and extrinsic nonlinearities. Extrinsic nonlinearities arise in transport modeling from forming ratios of two or more parameters in the governing equations. Intrinsic nonlinearities arise from equation parameters and properties that are functionally related to the dependent variables. For example, variations in the actual two-parameter transport response surface within a variably saturated zone represent a range of possible parameter estimation constraints. These possibilities include a welldefined global minimum with minimum parameter uncertainty, a global minimum with an intermediate amount of parameter uncertainty, a nearly perfect correlation, defined as an elongated trough, with a great amount of parameter uncertainty, a perfect correlation with infinite parameter uncertainty, multiple minima with little parameter uncertainty, or multiple minima with high parameter uncertainty (Friedel, 2005, 2006b). Potential regression pathways and corresponding estimated, best-fit parameter pairs are included to better illustrate the relation between the nonlinear parameter estimation process and potential reasons for parameter nonuniqueness and estimation uncertainty. 
Measurement information in the model calibration process constrains the solution space through interaction of the combinations of various parameter response surfaces (Carrera and Neuman, 1986b; Friedel, 2005). The best possible parameter estimation solution is when parameter values are uniquely defined by the intersection of parameter surfaces and therefore comprise a point (well-defined). In contrast, the worst parameter estimation solution is when the interaction of parameter response surfaces is poorly defined and has a large (poor or undefined) solution space. The interaction of parameter response surfaces in multi-dimensional parameter space is hard to visualize or quantify graphically, but the interaction of these response surfaces can be readily evaluated through inspection of the normalized eigenvector matrix (Doherty, 2004).

The normalized eigenvector matrix (derived from the corresponding covariance matrix) has as many eigenvectors and elements as the number of parameters being estimated. The eigenvectors themselves are arranged from minimum to maximum eigenvalues that correspond to a range of minimum to maximum model uncertainties. Because a principal component is determined by multiplying the parameter vector by the eigenvector matrix, the element values are interpreted as a measure of relative importance of associated parameters to an eigenvalue along the associated eigenvector (Friedel, 2005). More specifically, a parameter that is coincident with the eigenvector will have a value of 1 (direction cosine), whereas a parameter that is orthogonal and not associated with the eigenvector will have a value of 0 . In general, most parameters contribute uncertainty to varying degrees and therefore will have values between 0 and 1 . Those parameters with a shared predominance among an eigenvector are related and therefore represent correlation and the likelihood for parameter nonuniqueness and enhanced uncertainty. The modeler should concentrate on identifying and removing correlated parameters associated with eigenvectors characterized by the largest eigenvalues. In this way, the reduction in parameter complexity also reduces the model uncertainty (Friedel, 2006b, 2007).

\section{Model Quality}

Regardless of the model calibration approach used and the number of state variables, the calibrated model quality is typically judged on three qualities: the minimization of an objective function, the various model statistics (such as the mean and standard error of residuals, and model correlation coefficients), and parameter statistics that characterize the degree of uncertainty, which is either linear (Hill, 1998; Gandhi, and others, 2002; Gaganis and others, 2002) or nonlinear (Christensen and Cooley, 1999; Friedel, 2005, 2006). The ability to infer the quality of parameter 
estimates using linear statistics becomes less precise as the nonlinearity of the problem increases. For example, whereas ground-water models are considered slightly nonlinear, basin and variably saturated zone models are highly nonlinear. In the case of these nonlinear models, the computed linear confidence limits typically do not extend far enough in parameter space to capture the true central tendency and to reflect true asymmetric limits associated with a parameter (Friedel, 2005). For all degrees of nonlinearity, the residual objective function (measured at its minimum), the estimated limits of parameter uncertainty, the variation in eigenvalues, and the model condition number all underscore the presence of uncertainty. The fact that calibrated parameter values for basin, ground-water, or variably saturated models are uncertain despite their optimality suggests that flow and transport predictions made using a calibrated model also are likely to be uncertain. Therefore, it is in the best interest of the hydrologist to evaluate the prediction uncertainty.

\section{Model Validation}

Following the model calibration process, the calibrated model is usually tested in some kind of validation phase. Model validation tests the ability of a calibrated model to simulate some prescribed system behavior. The calibration process already represents a rudimentary model validation by attempting to minimize the misfit between simulated and observed dependent variables. This approach is inherently weak, however, because the calibrated model is limited to the information content within the measurement constraints. One common alternative is the so-called split sample approach, in which some portion of the observed measurements are randomly reserved for subsequent comparison against the model predictions. In this case, the model performance is determined on similar but independent data. The split-sample approach also is weak and suffers the disadvantage of removing already limited and expensive data from the calibration process. A more sophisticated, but less used, extension of the split-sample method is cross validation, where the model is developed on one randomly drawn half of the data and tested on the other half. The average is taken as an estimate of performance. This approach offers flexibility in omitting other fractions; for example, $10 \%$ of the observations reserved to test a model developed on the other $90 \%$. To improve the stability of the cross validation, the whole procedure can be repeated several times, taking new random sub-samples (Efron and Tishirani, 1997). Another common approach is to perform a post-audit analysis of model predictions. Historically, the literature is replete with post-audit analyses of calibrated models in which predicted future system behavior resulted in over or under predictions (Anderson and Bates, 2001). Whereas Bredehoeft (2005) associates these 
problems with the conceptual model, the author's experience is that model parameterization and limited information content in the calibration-constraints can contribute equally, if not more, to the overall prediction uncertainty.

\section{Predictive Uncertainty}

The early evaluations of prediction uncertainty in hydrologic systems modeling, whether of surface water, ground water, or variably saturated zones, used deterministic or stochastic assessments of parameter sensitivity by assigning random variables and applying a Monte Carlo sampling technique. Early sensitivity analyses were of limited value (for example, identifying the parameter exerting the greatest influence on the hydrologic system) because of the evaluation of single parameter values instead of the simultaneous evaluation of all parameters that is done using Jacobian matrix and composite-scaled sensitivity calculations (Hill, 1998; Friedel, 2005, 2006a).

The primary disadvantage in using a forward Monte Carlo modeling approach is that model parameter values are arbitrarily described as a random variable distribution, with no consideration for honoring field measurements (the dependent variables). In an effort to honor field measurements, researchers recently applied the Monte Carlo technique to estimated parameter values and their computed linear limits for a coupled, variably saturated system (Kwicklis and others, 2006). Such an approach is inappropriate because estimated parameter values do not represent median values, nor do the linear uncertainty limits extend far enough into parameter space, and because of the need to assume Gaussian random parameters when in fact they are not. To overcome the limitations with the traditional forward Monte Carlo approach in predictive analysis, hydrologists appropriately considered alternate inverse predictive analysis approaches, such as the generalized likelihood uncertainty estimation (Beven and Binley, 1992; Beven and Freer, 2001; Friedel, 2002, 2006a, 2006b), the direct estimation of the nonlinear predictive limits (Veccia and Cooley, 1987; McKenna and others, 2003; Friedel, 2002, 2005, 2006a, 2006b), and the Markov-Chain Monte Carlo method (Chen and Kao, 2002), among others.

The first and perhaps most widely used predictive analysis tool is the generalized likelihood uncertainty estimation method. This method requires the analysis of multiple inverse simulation scenarios based on uniform random sampling of the model parameter hyperspace. In cases where models are physically complex or highly nonlinear, such as for flow or transport in basins (Beven and Binely, 1992) or in variably saturated zones (Friedel, 2006b), this requirement is computationally prohibitive. There are also potential problems when the inverse method stalls in 
computing local minima, particularly for nonlinear problems and when using gradient-based parameter estimation algorithms.

A second alternative in predictive analysis is the direct estimation of nonlinear prediction limits (Veccia and Cooley, 1989). This method assumes that there is a best-fit set of nonunique model parameter values. That is, there is a single global minimum objective function value (determined, for example, using a calibrated model), but because of the limited information content used to constrain the solution space, there are infinite combinations of parameter value that satisfy the predictive solution. This method appears to be relatively robust. One disadvantage, however, is that one complete estimation problem must be solved for each prediction limit being evaluated.

A third alternative in the analysis of predictive uncertainty is the Markov-Chain Monte Carlo method (Kuczera, 1998; Campbell and others, 1999; Bates and Campbell, 2001). MarkovChain methods have become important for generating sequences of random numbers to accurately reflect complicated desired-probability distributions. In recent years this approach has improved the practicability of Bayesian inference methods. In hydrologic modeling, a Markov-Chain model is a dynamic hybrid of probability and matrix models. For example, the probability matrix of the Markov-Chain model can be determined from the ground-water table elevation/time series. In this case, the probability reflects the likelihood of the ground-water table changing between levels. The Shuffled Complex Evolution Metropolis method (Vrugt, 2003) was recently devised for single- and multi-objective calibration of hydrologic models. This algorithm is a general-purpose optimization algorithm that uses adaptive Markov-Chain Monte Carlo sampling to provide an efficient search of the parameter space. Whereas Markov-Chain Monte Carlo methods and similar approaches could be used in nonlinear predictive analysis, both the generalized likelihood uncertainty estimation and the direct estimation of nonlinear predictive uncertainty limits can be done using the modelindependent parameter estimation framework called PEST (Doherty, 2004). First, the hydrologist calibrates the numerical model and then estimates the limits of prediction using the direct approach integrated into PEST.

The ultimate goal of the model calibration process is to ensure that predictions are made with a minimum amount of uncertainty. The hydrologist should evaluate the effect of modifications to the conceptual model and the introduction of additional information on the range of predictive uncertainty. Likewise, eigenvector analysis may be used to reduce the model complexity, and the recalculation of predictive limits can assess the benefit toward reducing the prediction uncertainty. More important is the need to evaluate known or observed dependent 
variables with the limits of prediction uncertainty. Predictive uncertainty can be lessened by reducing model complexity, but this lessening often results in increased model prediction bias. Examples of the tradeoff between model complexity, prediction uncertainty, and model prediction bias are provided for predicting peak-flow discharge in a gaged basin (Friedel, 2006a, 2006b) and recurrent rainfall in several ungaged basins (Friedel, in press).

\section{Summary}

The ability of numerical models to provide reliable answers depends on the adequacy of the model structure, its parameterization, and the quality of field information. Assuming that the conceptual model structure and other model characteristics are adequate, parameterization can proceed either by directly assigning parameter values or by estimating them indirectly through a nonlinear inverse process. Because the inverse process honors dependent field measurements (such as head pressure, solute concentration, water temperature, and so on), one suggestion is to use the geostatistically-based parameter field as initial starting values (soft prior information) in a mathematically-based (gradient, genetic, or global search algorithm) estimation approach along with an objective function. Increasing the number and type of measurements is known to reduce model uncertainty; therefore, a least-squares measurement objective function is suggested, together with a regularization objective function. One form of regularization introduces into the objective function measures of dissimilarity across parameter space. This approach facilitates evolution of the covariance among parameter values as long as useful information exists in the constraint measurements. Whereas the set of parameter values is optimal in a best-fit sense, it is also nonunique due to uncertainty in the modeling process. For this reason, estimating the limits of predictive uncertainty is important, and the Veccia and Cooley (1987) approach is recommended. For cases of slightly nonlinear ground-water basins, the generalized likelihood uncertainty estimation approach could also be used. Re-evaluation of the range of prediction uncertainty is suggested if changes to the conceptual model or additional information are introduced into the calibration process. Finally, eigenvector analysis can be used to identify and remove parameters that cannot be well resolved. Evaluating the predictive uncertainty following any reduction to a model's structure or complexity should be considered iterative and useful for ensuring no introduction of prediction bias. 


\section{References Cited}

Abbaspour, K. C., van Genuchten, M. Th., Schulin, R., and Schlppi. E., 1997, A sequential uncertainty domain inverse procedure for estimating subsurface flow and transport parameters: Water Resources Research, v. 33, no. 8, p. 1879-1892.

Anderson, M.G., and Bates, P.D., 2001, Model validation: perspectives in hydrological science. Wiley: Chichester, 219 p.

Bates, B.C., and Campbell, E.P., 2001, A Markov Chain Monte-Carlo scheme for parameter estimation and inference in conceptual rainfall-runoff modeling, Water Resources Research, v. 37, no. 4, p. 937-947.

Benito Garcia-Morales M., and Beucher H., 2002, Inference of the boolean model on a non stationary case. In: 8th annual conference of the international association for mathematical geology, Berlin, 15-20 September 2002. p. 167-172

Beven, K.J., and Binley, A.M., 1992, The future of distributed models: model calibration and uncertainty prediction: Hydrological Processes, v. 6, p.279-298.

Beven, K.J., and Freer, J., 2001, Equifinality, data assimilation, and uncertainty estimation in mechanistic modelling of complex environmental systems: Journal of Hydrology, v. 249, p. 11-29.

Bravo, H.R., Feng, J., Hunt, R.J., 2002, Using groundwater temperature data to constrain parameter estimation in a groundwater flow model of a wetland system: Water Resources Research, v. 38, p. 1-14.

Bredehoeft, J., 2005, The conceptualization model problem - surprise: Hydrogeology Journal, V. 13, p. $37-46$.

British Geological Survey, 1996, First Projet de renforcement Institutionnel du Secteur Minier (PRISM-1), $132 \mathrm{p}$. 
Bui E., and Moran, C., 1995, Using soil survey data to identify potential areas of groundwater recharge and saline discharge: ACLEP Newsletter; v. 4, no. 4, p. 2-5.

Carl, S.F., and Fogg, G.E., 1996, Transition probability-based indicator geostatistics: Mathematical Geology, v. 28, no. 4, p. 453-476.

Campbell, E.P., Fox, D.R., and Bates, B.C., 1999. A Bayesian approach to parameter estimation and pooling in nonlinear flood event models, Water Resources Research, v. 35, no. 1, p. 211-220.

Carrera, J., and Neuman, S.P., 1986a, Estimation of aquifer parameters under transient and steady state conditions: 1. Maximum likelihood method incorporating prior information: Water Resources Research, v. 38, no.28, p. 1-14.

Carrera, J., and Neuman, S.P., 1986b, Estimation of aquifer parameters under transient and steady state conditions: 2. Uniqueness, Stability, and Solution Algorithm: Water Resources Research, v. 38 , no. 28 , p. 1-14.

Chen, J., Hubbard, S., Rubin, Y., Murray, C., Roden, E., and Majer, E., 2004, Model calibration and predictive analysis: Water Resources Research, v. 40, no. W12412, p. 1-14.

Chen WY, and Kao, J.J., 2002, A fuzzy Markov approach for assessing groundwater pollution potential for landfill siting: Waste Management Research, v. 20, no. 2, p. 187-197.

Christensen, S., and Cooley, R.L., 1999, Evaluation of confidence intervals for a steady-state leaky aquifer model: Advances in Water Resources, v. 22, no. 8, p. 807-817.

Clifford, P., 1993, Discussion on the meeting on the Gibbs sampler and other Markov chain Monte Carlo methods: Journal of the Royal Statistical Society, v. 55, p. 53-54.

Desbarats, A. J., and Bachu, S., 1994, Geostatistical analysis of aquifer heterogeneity from the core scale to the basin scale, A case study: Water Resources Research, v. 30, no. 3, p. 673-684. 
Dietrich, C. R., and Osborn, M. R., 1991, Estimation of covariance parameters in kriging via restricted maximum likelihood: Mathematical Geology, v. 23, no. 1, p. 119-135.

Doherty, J., 2004, PEST: Model-Independent Parameter estimation. Version 5 of User Manual. Watermark Numerical computing, Brisbane, Australia, 213 p.

Elfeki, A., and Dekking, M., 2001, A Markov chain model for subsurface characterization: Theory and applications: Mathematical Geology, v. 33, p. 569-589.

Essaid, H.I., Cozzarelli, I.M., Eganhouse, R.P., Herkelrath, W.N., Bekins, B.A., and Delin, G.N., 2003, Inverse modeling of BTEX dissolution and biodegradation at the Bemidji, MN crude-oil spill site: Journal of Contaminant Hydrology, v. 67, p. 269-299.

Friedel, M.J., 2002, Quantifying ground-water recharge using a coupled water-heat-solute transport model: optimal nonlinear parameter estimation and predictive uncertainty: EOS Trans. AGU, 83(47), Fall Meet. San Francisco, CA, Suppl., Abstract H21D-8060.

Friedel, M. J., 2005, Coupled inverse modeling of vadose zone water, heat, and solute transport: calibration constraints, parameter nonuniqueness, and predictive uncertainty: Journal of Hydrology, v. 312, no. 1-4, p. 148-175.

Friedel, M. J., 2006a, Predictive streamflow uncertainty in relation to calibration-constraint information, model complexity, and model bias: International Journal of River Basin Management, v. 4, no. 1, p. 1-15.

Friedel, M. J., 2006b, Reliability in estimating urban groundwater recharge through the vadose zone: managing sustainable development in arid and semiarid regions. In: Tellam, J.H., Rivett, M.O., and Israfilov, R.G. (eds), Urban groundwater management and sustainability. NATO Science Series, IV. Earth and Environmental Sciences, Springer, Dordrecht, The Netherlands, v. 74, p. 169-182. 
Friedel, M. J., Smith, M.E., A.M., Erazo, and Litke, D., in press, Probable flood predictions in ungaged coastal basins of El Salvador: Journal of Hydrologic Engineering, p. X-X.

Friedel, M. J., in press, Predicting probable rainfall in ungaged coastal basins of El Salvador: Natural Hazards Journal, p. X-X.

Gaganis, P., Karapanagioti, H.K., and Burganos, V.N., 2002, Modeling multicomponent NAPL transport in the unsaturated zone with the constitutive averaging technique: Advances in Water Resources: v. 25, p. 723-732.

Gandhi, R. K., Hopkins, G.D., Goltz, M.N., Goerlick, S.M., and McCarty, P.L, 2002, Full-scale demonstration of in situ cometabolic biodegradation of trichloroethylene in groundwater 1 . Dynamics of a recirculating well system: Water Resources Research, v. 36, no. 4, p. 10 - 16.

Hendricks-Franssen, H. J., Gomez-Haernandez, J. J., and Sahuquilo, A., 2003, Coupled inverse modeling of groundwater flow and mass transport and the worth of concentration data: Journal of Hydrology, v. 281, no. 4, p. 281-295

Hill, M., 1998, Methods and guidelines for effective model calibration: U.S. Geological Survey Water Resources Investigation Report, 98-4005, 90 p.

Hoeksema, R. J., Kitanidis, P. K., 1984, An Application of the Geostatistical Approach to the Inverse Problem in Two-Dimensional Groundwater Modeling: Water Resources Research, v. 20, no. 7 , p. $1003-1020$.

Inoue, M., Simunek, J., Shiozawa, S., and Hopmans, J. W., 2000, Estimation of soil hydraulic and solute transport parameters from transient infiltration experiments: Advances in Water Resources, v. 23, p. 677-688.

Izbicki, J., Radyk, J., and Michel, R.L., 2000, Water movement through a thick unsaturated zone underlying an intermittent stream in the western Mojave Desert, southern California, USA: Journal of Hydrology, v. 238, p. 194-217. 
Kuczera, G. and Parent, E., 1998, Monte Carlo assessment of parameter uncertainty in conceptual catchment models: the Metropolis algorithm, Journal of Hydrology, v. 211, p. 69-85.

Kwicklis, E.M, Wolfsberg, A.V., Stauffer, P.H., Walvoord, M.A., and Sully, M.J., 2006, Multiphase, Multicomponent Parameter Estimation for Liquid and Vapor Fluxes in Deep Arid Systems Using Hydrologic Data and Natural Environmental Tracers: Vadose Zone Journal., v. 5, p. $934-950$.

Li, W., C. Zhang, Burt, J.E., Zhu, A.-X., and Feyen, J., 2004, Two-dimensional Markov chain simulation of soil type spatial distribution: Soil Science Society American Journal, v. 68, p. 1479-1490.

McLaughlin, D., Townley, L.R., 1996, A reassessment of the groundwater inverse problem: Water Resources Research, v. 32, no. 5, p. 1131-1161.

McKenna, S.A., Doherty, J., Hart, D.B., 2003, Non-uniqueness of inverse transmissivity field calibration and predictive transport modeling: Journal of Hydrology, v. 281, p. 263-280.

Medina, A., Carrera, J., 1996, Coupled estimation of flow and solute transport parameters: Water Resources Research, v. 32, p. 3063-3076.

Mehl, S., and Hill, M., 2001, A comparison of solute-transport solution techniques and their effect on sensitivity analysis and inverse modeling results: Ground Water, v. 39, no. 2, p. 300-307.

Mishra, S., Parker, J.C., and Singhal, N., 1989, Estimation of soil hydraulic properties and their uncertainty from particle size distribution data: Journal of Hydrology, v. 108, p. 1-18.

Norberg, T., Rosen, L., Baran, A., and Baran, S., 2002, On modeling discrete geological structure as Markov random fields: Mathematical Geology, v. 34, p. 63-77. 
Pang, L., Close, M.E., Watt, J.P.C., and Vincent, K.W., 2000, Simulation of picloram, atrazine, and simazine leaching through two New Zealand soils and into groundwater using HYDRUS-2D: Journal of Contaminant Hydrology, v. 44, p. 19-46.

Rouhani, S., and Myers, D. E., 1990, Problems in space-time kriging of geohydrological data: Mathematical Geology, v. 22, no. 5, p. 611-623.

Rouhani, S., and Wackernagel, H., 1990, Multivariate geostatistical approach to Space-Time Data Analysis: Water Resources Research, v. 26, no. 4, p. 585-591.

Shafer, J. M., and Varljen, M. D., 1990, Approximation of Confidence Limits on Sample Semivariograms From Single Realizations of Spatially Correlated Random Fields: Water Resources Research, v. 26, no. 8, p. 1787-1802.

Seifert, D., and Jensen, J.L, 1999, Using sequential indicator simualation as a tool in reservoir description, issues, and uncertainties: Mathematical Geology, v. 31, p. 527-550.

Simunek, J., M., Th. van Genuchten, Gribb, M. M., Hopmans, J. W., 1998, Parameter estimation of unsaturated soil hydraulic properties from transient flow processes: Soil \& Tillage Research, v. 47 no. 1-2, p. 27-36.

Sonneberg, T.O., Engesgaard, P., Rosbjerg, D., 1996, Contaminant transport at a waste residue deposit 1. Inverse flow and nonreactive transport modeling: Water Resources Research, v. 32, no. 4, p. 925-938.

Sun, N, Yeh, W.G., 1990, Coupled inverse problems in groundwater modeling 2. Identifiability and experimental design: Water Resources Research, v. 26, no. 10, p. 2527-2540.

Tikhonov, A. and Arsenin, V., 1977, Solutions of ill-posed problems. Amsterdam, Winston and Sons, 423 p. Takyi, A.,K., and Lence, B.J., 1995, Markov chain model for seasonal-water quality management: Journal of Water Resources Planning and Management, v. 121, no. 2, p. 144-157. 
Vecchia, A.V. and Cooley, R.L., 1987, Simultaneous confidence intervals and prediction intervals for nonlinear regression models with application to a groundwater flow model: Water Resources Research, v. 23, no. 7, p. 1237-1250.

Vrugt, J.A., Gupta, H.V., Bouten, W., and Sorooshian, S., 2003, A Shuffled Complex Evolution Metropolis algorithm for optimization and uncertainty assessment of hydrologic model parameters: Water Resources Research, v. 39, no. 8, p. 149-188.

Woodbury, A. D., and Smith, L., 1988, Simultaneous inversion of hydrogeologic and thermal data: 2. Incorporation of thermal data: Water Resources Research, v. 24, no. 3, p. 356-372.

Zhang, C. and Li, W., 2005, Markov chain modeling of multinomial land-cover classes: GIScience Remote Sensing, v. 42, p. 1-18. 